\title{
Evaluation of a communication skills training to facilitate addressing palliative care related topics in advanced cancer patients: study protocol of a multicenter randomized controlled trial (PALLI-KOM)
}

Nele Harnischfeger ${ }^{1 *}$ D. Hilke M. Rath², Anneke Ullrich ${ }^{1}$, Bernd Alt-Epping ${ }^{3}$, Anne Letsch ${ }^{4}$, Peter Thuss-Patience ${ }^{5}$, Carsten Bokemeyer ${ }^{1}$, Karin Oechsle ${ }^{1 \dagger}$ and Corinna Bergelt ${ }^{2 \dagger}$

\begin{abstract}
Background: Early integration of palliative care concurrently to standard cancer care is associated with several benefits for patients and their caregivers. However, communication barriers on part of the caring physicians often impede a timely referral to palliative care. This study describes the protocol of the evaluation of a communication skills training aiming to strengthen the ability of physicians to address palliative care related topics adequately and early during disease trajectory.

Methods: We will implement a communication skills training and evaluate it within a prospective, multi-centered, two-armed randomized controlled trial (RCT), which will be conducted at four sites in Germany. Eligible subjects are all physicians treating patients with advanced cancer in their daily routine. An intervention group (IG) receiving a group training will be compared to a wait-list control group (CG) receiving the training after completion of data collection. At pre- and post-measurement points, participants will conduct videotaped conversations with standardized simulated patients (SP). Primary outcome will be the external rating of communication skills and consulting competencies addressing palliative care related topics. Secondary outcomes on core concepts of palliative care, basic knowledge, attitudes, confidence and self-efficacy will be assessed by standardized questionnaires and self-developed items. A further external assessment of the quality of physician-patientinteraction will be conducted by the SP. Longitudinal quantitative data will be analyzed using covariate-adjusted linear mixed-models.

\footnotetext{
* Correspondence: n.harnischfeger@uke.de

${ }^{\dagger}$ Karin Oechsle and Corinna Bergelt contributed equally to this manuscript and share last authorship.

'Department of Oncology, Hematology and BMT, Palliative Care Unit,

University Medical Center Hamburg-Eppendorf, Martinistraße 52, 20246 Hamburg, Germany

Full list of author information is available at the end of the article
}

(c) The Author(s). 2020 Open Access This article is licensed under a Creative Commons Attribution 4.0 International License, which permits use, sharing, adaptation, distribution and reproduction in any medium or format, as long as you give appropriate credit to the original author(s) and the source, provide a link to the Creative Commons licence, and indicate if changes were made. The images or other third party material in this article are included in the article's Creative Commons licence, unless indicated otherwise in a credit line to the material. If material is not included in the article's Creative Commons licence and your intended use is not permitted by statutory regulation or exceeds the permitted use, you will need to obtain permission directly from the copyright holder. To view a copy of this licence, visit http://creativecommons.org/licenses/by/4.0/. The Creative Commons Public Domain Dedication waiver (http://creativecommons.org/publicdomain/zero/1.0/) applies to the data made available in this article, unless otherwise stated in a credit line to the data. 
(Continued from previous page)

Discussion: If the communication skills training proves to be effective, it will provide a feasible intervention to promote an earlier communication of palliative care related topics in the care of advanced cancer patients. This would help to further establish early integration of palliative care as it is recommended by national and international guidelines.

Trial registration: German Clinical Trials Register DRKS00017025 (date of registration: 4 June 2019).

Keywords: RCT, Palliative care, Education, Communication skills training, Advanced cancer, Oncology, Physicianpatient-communication, Early integration of palliative care

\section{Background}

Complex psychological and physical symptoms of patients with advanced cancer often arise early during disease trajectory [1]. That is why palliative care, which focusses on identifying and addressing various physical, psychosocial and spiritual needs of patients with lifethreatening illnesses, should not only be provided at a stadium close to death, but concurrently with oncological treatment [2].

Multiple studies, including several randomized controlled trials, have shown the benefits of early implementation of palliative care concurrently to standard cancer care for patients and their caregivers. It is for example associated with improved symptom control, quality of life and mood, satisfaction with care, coping, understanding of disease and communication about care [39]. It can also lead to a decrease in chemotherapy use near end of life and therefore reduce treatment costs [7, 10]. Besides, it has been shown that patients suffering from advanced cancer prefer an early talk about end-oflife topics [11-14].

Addressing palliative care and end-of-life topics should be initiated by the primary care provider of the cancer patient $[15,16]$. Since not every patient is cared for by an oncologist, but by other specialists such as gynaecologists, urologists, etc. [17], all physicians treating patients with advanced cancer should aim for early implementation of palliative care into standard oncology care.

Early integration is also recommended by national and international guidelines $[2,15,18,19]$. The basis and central component of it is communication [20], which at the same time impedes it. Previous findings show that if conversation about palliative care and end-of-life topics occur, then usually too late, when patients are no longer able to decide for their own or already are in crisis [21]. This indicates that physicians seem to avoid referring to palliative care services, which has been confirmed in previous research [22, 23]. Studies and reviews report several reasons and possible barriers to referring to palliative care services. An important barrier is a lack of physicians' expert knowledge in palliative care, including a wrong understanding of this discipline [24]. A majority of physicians falsely equates palliative care with end-of- life care and associates it with imminent death [16], which often results in the fear of demoralizing the patient when addressing palliative care [23]. Another key reason represents the perceived difficulty to address end-of-life topics [11]. It is reported to be one of the most stressful and difficult parts within oncological treatment [25]. That discomfort is especially based on a high communicative uncertainty $[11,24]$. Besides the concern of causing stress in the patients [24], also personal reasons like prior traumatic experiences [22] may lead to a lack of discussing palliative care. Thus, also the physicians' own attitudes and fears towards death seem to play a role when avoiding such consultations $[26,27]$.

These aspects illustrate that physicians would benefit from offers to facilitate addressing palliative care in medical consultations with cancer patients. This is confirmed by the fact that physicians themselves demand for more education on communication in palliative care [28]. Strengthening physicians' communication skills and reducing individual insecurities would as a result promote the timely involvement of palliative care into standard cancer care, as it is required by clinical guidelines $[2,15$, 18, 19].

Various studies provide evidence for the effectiveness of communication skills trainings in oncological settings [29-32]. Also, trainings focusing on communication with regard to specific facets of palliative care, such as the transition to palliative care, have shown to be useful $[30,33]$. Those trainings in most cases refer to rehearsing one specific conversation, in which the respective topic is communicated [30, 33, 34].

Until now there are no training programs which address the general ability of physicians to talk about different topics relevant to palliative care, to allow for a gradual integration of this field. Also, most existing training programs are designed for oncologists and not open to physicians of different specialisation. Moreover, previous trainings are often very intensive and timeconsuming, sometimes lasting multiple days [35].

The objective of this study is to carry out an evaluation of a newly developed communication skills training within a randomized controlled trial. The training aims at strengthening the physicians' ability to address 
palliative care related topics adequately and early during disease trajectory.

The main research question is:

- Does the training improve communication skills and consulting competencies addressing palliative care related topics?

Further research questions concerning the effectiveness and acceptance of the training are:

- Does the training improve the quality of physicianpatient interaction in conversations about palliative care?

- Does the training support physicians to consider palliative care principles, such as psychosocial needs, within the consultation?

- Does the training improve the perceived confidence of physicians dealing with palliative care related topics?

- Does the training enhance self-efficacy regarding conversations about palliative care?

- Does the training change the physicians' attitude towards caring for terminally ill patients and communicating about dying and death?

- Does the training improve basic knowledge about palliative care services?

- What is the level of acceptance and satisfaction with the training?

\section{Methods}

\section{Design}

The planned evaluation is designed as a prospective, multi-centered, two-armed randomized controlled trial (RCT).

The aim of the study is to investigate the effect of an intervention with regard to communication about palliative care. It will be carried out at four locations in Germany. Physicians of different specialist qualifications will be recruited and randomly assigned to an intervention group (IG) receiving the communication skills training and a wait list control group (CG). Data of both groups will be assessed 6 to 10 weeks before (baseline, T0) and 6 to 10 weeks after the training (T1). The CG will be assessed at parallel time-points and will attend the training after the end of data collection.

\section{Cooperation partners}

The study will be carried out at four sites with partners with long-term experience in palliative care. Study sites are located at the University Medical Center HamburgEppendorf, the University Medical Center Goettingen, the University Medical Center Schleswig-Holstein and the Charite University Medicine Berlin. Trainings and data collection will be carried out at all four locations. Coordination, training development and data analysis will mainly be conducted in Hamburg, where the principal investigator and the study management are situated.

\section{Inclusion and exclusion criteria}

Eligible for the RCT are physicians who treat cancer patients in their daily routine but are not specialized in palliative care. Participation is not limited to medical oncologists, but open to all physicians treating cancer patients (such as gynecologists, dermatologists, urologists etc.). Participants must provide informed consent for participation in the study. Exclusion criteria are a palliative care specialist training level as well as insufficient German language skills, since the training is conducted in German.

\section{Development of the intervention}

The communication skills training was developed based on literature and four focus groups (with $N=28$ participants). Within the focus groups the perceptions and needs of physicians treating advanced cancer patients were assessed. Results were merged with relevant aspects from literature, such as the core competencies in palliative care defined by the European Association for Palliative Care (EAPC) [36]. The training was manualized following the CReDECI2-Guidelines (Criteria for Reporting the Development and Evaluation of Complex Intervention in healthcare: revised guideline) [37].

The newly developed communication skills training consists of two sessions each lasting $90 \mathrm{~min}$. It includes short theoretical presentations, written information, audiovisual contents as well as behavioral exercises for active learning. Video material of an expert leading a conversation with a standardized simulated patient (SP) will be presented as a positive example within the training. The intervention is intended to promote the three components of the 'KSA-Framework' (Knowledge, Skills, Attitude) [38]. The component 'knowledge' includes theory on communication (e.g. specific skills, empathy, dealing with palliative care and end-of-life issues), core principles and concepts of palliative care (e.g. double awareness) and palliative care services. 'Skills' will be promoted through rehearsing conversations in role plays with SPs based on case vignettes of advanced cancer patients, which is an effective training strategies for communication skills trainings [39]. 'Attitude' will be addressed through the transmission of a new attitude towards palliative care and dealing with advanced cancer patients.

\section{Train-the-trainer workshop}

As recommended in guidelines on communication skills trainings [32], the study partners who will conduct the training will attend a train-the-trainer workshop, which 
will be carried out by the coordinating center. The main content will be the correct implementation of the training manual. Moreover, participants will be taught how to train future study staff as well as instructing SPs for the consultations pre and post training in the IG and CG. When SPs will be briefed in the respective study sites, a member from the principal investigator's team will be present to ensure standardization.

\section{Evaluation of the training (RCT)}

The communication skills training will be implemented and evaluated. The procedure of the RCT is presented in Fig. 1. The IG will receive the training between the two measurement points, while the control group receives it after the end of data collection.

\section{Sample size and power}

Sample size calculation indicates that a total sample size of 134 participating physicians (67 per group) is needed to detect medium group differences (Cohen's $d=0.5$ ) in a two tailed test with a power of $0.80(80 \%)$ at a significance level of $p<0.05$. A medium correlation $(r=0.3$ [40]) between initial level and outcome measurement is assumed. Based on an estimated dropout-rate of $30 \%$, recruitment of 174 physicians (87 per group) is necessary.

This amount of participating physicians will be recruited consecutively in groups of 10 and equally divided between the four study sites. For the recruitment, information material will be spread in local oncological networks, at conferences and events.

\section{Randomization}

Computer generated randomization for all study sites will be performed by an experienced independent coworker from the statistical-methods-group of the Department of Medical Psychology at the University Medical Center Hamburg-Eppendorf. Randomization will be conducted separately per site. Since participants will be recruited consecutively, block randomization with block sizes of 20 will be applied. Within every block of 20 participants at each study site, 10 will be assigned to IG and 10 to CG. Allocation ratio of 1:1 will be used.

\section{Study intervention}

The communication skills training will be conducted with up to 10 physicians per group. Each cooperating site will consecutively run 2-3 training cycles. The training of each group will consist of two sessions, each lasting $90 \mathrm{~min}$. There will be approximately two weeks between both sessions. The training will be carried out by two trainers: the leading investigator of the respective study site with expert knowledge in palliative care and a researcher with expert knowledge in communication and psychooncology. Contents and schedule are

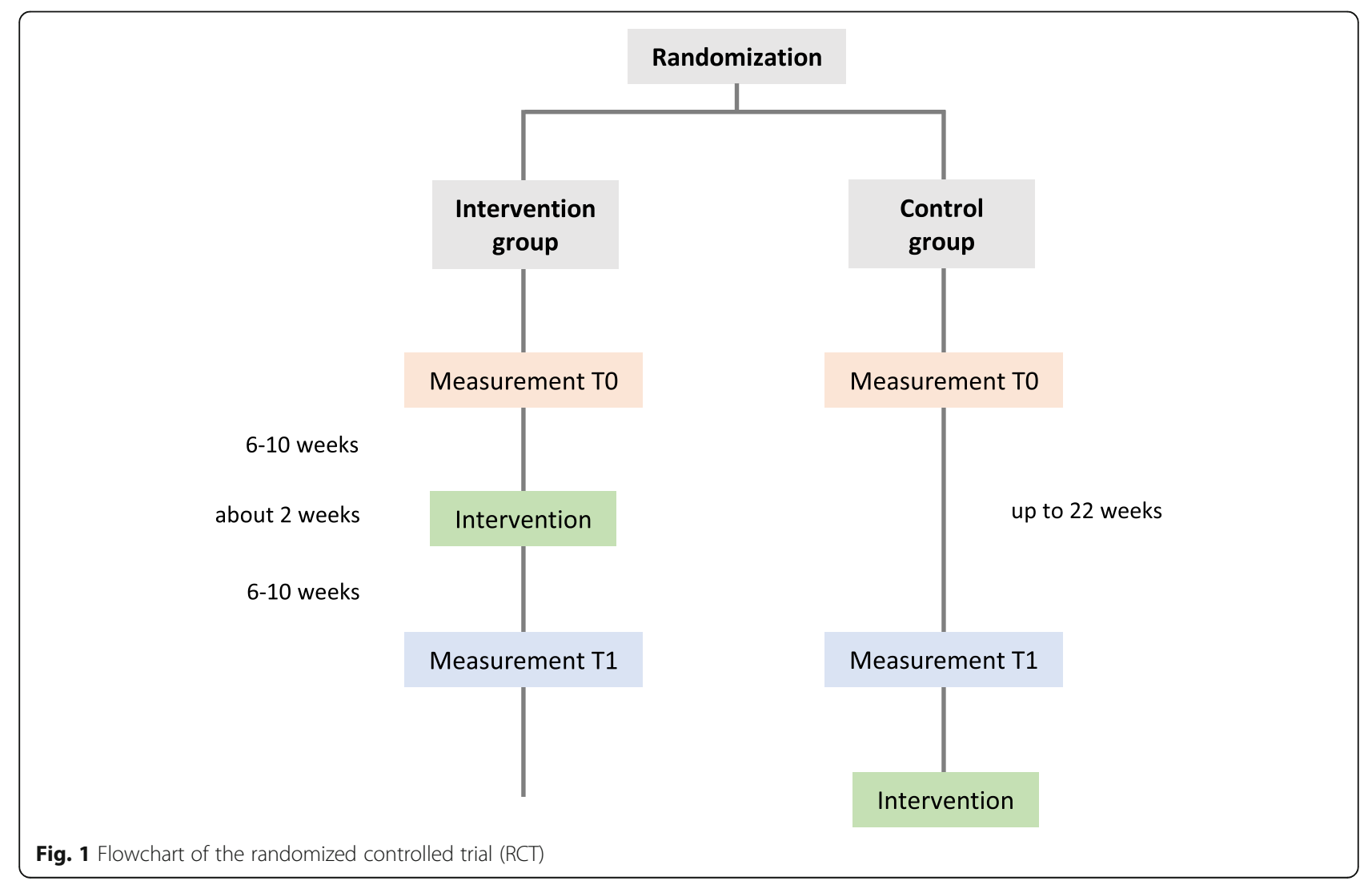


standardized through the manual. To ensure adherence, the trainers will fill out a training protocol after the training.

\section{Evaluation}

The evaluation of the training will be carried out by comparing the pre (T0)-post (T1) differences of consultation performance of the IG and the CG. Therefore, the participants of IG and CG will conduct a videotaped medical consultation on palliative care related topics with a SP at T0 and T1. The consultations will be arranged individually between the physician and the SP and will take place in the familiar working environment of the physician. No further study assistant will be present, so that the setting is kept as naturalistic as possible.

\section{Outcomes and measurement}

Table 1 displays an overview of collected data, instruments, measurement points and sources of data. Measurements consist of external and self-assessed items. The following instruments will be used regarding our primary and secondary study outcomes.

\section{Primary outcome}

Communication skills and consulting competencies addressing palliative care related topics In order to assess the consultation performance of the physicians, we will develop different case vignettes, which will be varied systematically between the measurement points. While the severity of the disease will be comparable, the type of symptoms and the patient's needs will differ from case to case.

Communication skills and consulting competencies addressing palliative care related topics will be assessed by the research team using the German version of the COM-ON-checklist $\quad(\mathrm{COM}-\mathrm{ON}=$ Communication in Oncology) [41], which is a valid instrument for the external assessment of communication behavior of oncologists consisting of 5 scales and 31 Items. Researchers will rate the videotaped physician-patient-consultations on a 5-point Likert scale by the following scales: general communication skills, specific skills: transition to palliative care, involvement of relatives and overall evaluation items. The fifth scale named disclosing information about clinical trials will be excluded, because in this context no such information has to be given, so that only 21 items are used. The instrument has proved to be valid and reliable [41].

To ensure independent and blinded rating of the consultation, we will rotate the videotapes between the four research sites. Thus, the rater will not have any information on group membership (IG or CG) of the respective participant.

\section{Secondary outcomes: external assessments}

Consideration of palliative care principles We will develop a study-specific questionnaire consisting of items based on the EAPC-competencies [36] to assess the application of palliative care principles. With this questionnaire the consultation competence regarding palliative care will be externally assessed by the researchers.

Table 1 Overview of study measures

\begin{tabular}{|c|c|c|c|c|}
\hline Measures & Instrument & $\begin{array}{l}\text { Baseline/ } \\
\text { Pre- } \\
\text { Training } \\
\text { (T0) }\end{array}$ & $\begin{array}{l}\text { Post- } \\
\text { Training } \\
\text { (T1) }\end{array}$ & Source of data \\
\hline $\begin{array}{l}\text { Communication skills and consulting } \\
\text { competencies addressing palliative care related } \\
\text { topics }\end{array}$ & German version of the COM-ON-Checklist & $\bullet$ & $\bullet$ & $\begin{array}{l}\text { External assessment } \\
\text { by researchers }\end{array}$ \\
\hline Consideration of palliative care principles & $\begin{array}{l}\text { Self-developed questionnaire based on EAPC- } \\
\text { competencies }\end{array}$ & $\bullet$ & $\bullet$ & $\begin{array}{l}\text { External assessment } \\
\text { by researchers }\end{array}$ \\
\hline Quality of physician-patient-interaction & $\begin{array}{l}\text { German version of the Questionnaire on the } \\
\text { Quality of Physician-Patient-Interaction (QQPPI) }\end{array}$ & $\bullet$ & $\bullet$ & $\begin{array}{l}\text { External assessment } \\
\text { by simulated patients }\end{array}$ \\
\hline Sociodemographic data & Self-developed items & $\bullet$ & & Physician self-report \\
\hline $\begin{array}{l}\text { Confidence in dealing with palliative care related } \\
\text { topics }\end{array}$ & Self-developed items & $\bullet$ & $\bullet$ & Physician self-report \\
\hline $\begin{array}{l}\text { Self-efficacy regarding conversations about } \\
\text { palliative care }\end{array}$ & $\begin{array}{l}\text { German version of Self-Efficacy in Palliative Care } \\
\text { Scale (SEPC) }\end{array}$ & $\bullet$ & $\bullet$ & Physician self-report \\
\hline Attitude towards caring for terminally ill patients & German version of Thanatophobia-Scale & $\bullet$ & $\bullet$ & Physician self-report \\
\hline Knowledge about palliative care services & Self-developed items & $\bullet$ & $\bullet$ & Physician self-report \\
\hline Acceptance of and satisfaction with training & Self-developed items & & $\bullet$ & Physician self-report \\
\hline
\end{tabular}


Quality of physician-patient-interaction A further external evaluation of the consultation is carried out by the SPs with the German version of the Questionnaire on the Quality of Physician-Patient-Interaction (QQPPI) [42]. A 5-point Likert-scale from (1) strongly disagree to (5) strongly agree is used. The total score is determined by the mean value of all items. The instrument has proved to be valid and reliable [42].

\section{Secondary outcomes: self-report}

Confidence in dealing with palliative care related topics The physician's perceived confidence will be assessed by study-specific, self-developed items.

Self-efficacy regarding conversations about palliative care A German version of the Self-Efficacy in Palliative Care Scale (SEPC) [43] will be used to assess self-efficacy. It consists of 23 items, which assess the constructs of selfefficacy and outcome expectancies in palliative care. Each subscale represents different target behaviors and skills, upon which the study participant rates his or her confidence in his or her ability to perform the respective behavior or skill on a $100 \mathrm{~mm}$ visual analogue scale ranging from (0) very anxious to (10) very confident. The SEPC is a valid and reliable questionnaire [43].

Attitude towards caring for terminally ill patients To measure this construct, we will make use of the Thanatophobia-Scale [44], a short questionnaire that addresses feelings associated with fear of death among healthcare professionals. The 7 items measure discomfort in dealing with dying patients on a seven-point Likert scale ranging from (1) strongly disagree to (7) strongly agree. A total score is calculated by summing all items. The Thanatophobia-Scale has proved to be valid and reliable $[43,44]$.

Knowledge about palliative care services Basic knowledge concerning palliative care services will be assessed by study-specific, self-developed items.

Acceptance of and satisfaction with the training The participants' perception concerning the quality of the training will be assessed after the training by studyspecific, self-developed items, supplemented by few open questions.

\section{Data analyses}

This study is a multivariate, two-armed RCT with repeated measurement points across time. Descriptive statistics will be used to characterize and describe groups (IG and CG). Using univariate analyses (t-test, analysis of variance) or comparable non-parametric tests (chi- square-tests, U-tests), differences between subgroups (e.g. age, medical specialization, level of working experience, work setting) will be explored.

In order to measure the success of the training, covariate-adjusted linear mixed models will be conducted for analyzing primary and secondary outcome variables. The considered covariates will be the initial level of outcome variables at T0. This method allows to also consider missing data. For non-repeated continuous and binary measurements, ordinary linear regression and logistic models will be used.

\section{Study status}

The project duration is 36 months. The study was initiated in March 2019. The first 12 months are dedicated to the first study phase including extensive preparatory work, focus groups as well as development and manualization of the training. Recruitment of participants will start in April 2020. Data collection of both measurement points is planned to be completed by October 2021 .

\section{Ethics and consent}

We will provide written information material to study participants and SP, who both must provide informed consent before data collection. The study protocol and other requested documents were reviewed and approved by the medical ethics committee of the Medical Chamber of Hamburg (date: 19 November 2018, number: PV5910).

\section{Data confidentiality}

To ensure confidentiality, data will be stored pseudonymized on a secure database in accordance with the General Data Protection Regulations [45]. Information and measurements of the study participants collected during the study will be stored separately from the personal information. Extensive considerations on data protection with the data protection officer of the University Medical Center Hamburg-Eppendorf were carried out.

\section{Discussion}

The aim of this study project is to evaluate a communication skills training that addresses physicians' ability to communicate adequately and early about palliative care related topics. To the best of our knowledge, this is the first randomized controlled trial for such training. Few communication skills trainings on palliative care related topics do exist, but those solely focus on communicating single, specific facets of palliative care [30, 33, 34].

earlyEarly integration of palliative care into the care of advanced cancer patients is recommended by various guidelines $[2,15,18]$. However, different barriers on part of the physicians impede this. A major barrier and reason for the avoidance of referring to palliative care is 
communicating the associated topics to patients, which at the same time is regarded a fundamental component of integration [20]. Once completed, the project will provide an evidence-based approach to reduce those communication barriers. Accordingly, future use of the training program will promote an earlier referral to palliative care in the care of advanced cancer patients. This is associated with several advantages not only for patients and their caregivers, but also for the health care system, as it reduces costs [15] by providing less aggressive care at the very end of life [46]. Since the training is designed for physicians of different specialization treating cancer patients, the intervention addresses a broad clientele. The assessment of several outcome variables with external and selfassessment instruments in our study will allow for a comprehensive, multiperspective insight into the effectiveness of the training. This will enable conclusions on future interventions, further research and the feasibility of similar trials. A limitation of the study represents a potential selection bias. Due to the voluntary participation, it might be that those physicians take part, who already have a higher interest or competence in physician-patient communication. However, ethical guidelines prevent a subsequent non-responder analysis, so that this circumstance cannot be analyzed.

The study results will be disseminated through publication in peer-reviewed scientific journals and presentations on scientific meetings and conferences.

In conclusion, this randomized controlled trial will provide a feasible intervention designed for a broad range of recipients to promote earlier communication about palliative care and end-of-life topics.

\section{Abbreviations \\ CG: Control group; COM-ON: Communication in Oncology; CReDECI2: Criteria for Reporting the Development and Evaluation of Complex Intervention in healthcare; EAPC: European Association for Palliative Care; IG: Intervention group; KSA: Knowledge, Skills, Attitude; QQPPI: Questionnaire on the Quality of Physician-Patient-Interaction; RCT: Randomized controlled trial; SEPC: Self- Efficacy in Palliative Care Scale; SP: Simulated patients}

\section{Acknowledgements}

Not applicable.

\begin{abstract}
Authors' contributions
$\mathrm{AU}, \mathrm{KO}$ and $\mathrm{CBe}$ developed the study concept and the design. $\mathrm{NH}, \mathrm{HR}, \mathrm{KO}$ and $\mathrm{CBe}$, developed the intervention based on the literature and focus group data. NH drafted the manuscript, which was modified and supplemented by all other authors. NH, HR, BAE, AL, PTP, CB, KO and CBe recruit patients. $\mathrm{NH}, \mathrm{HR}, \mathrm{BAE}, \mathrm{AL}, \mathrm{PTP}, \mathrm{KO}$ and $\mathrm{CBe}$ conduct the interventions. All authors were involved in revising the manuscript substantively, and read and approved the final manuscript.
\end{abstract}

\section{Funding}

The study is funded after peer review by the German Cancer Aid (Deutsche Krebshilfe; grant number: 70113231). The funding source is not involved in the study design, the collection, analysis and interpretation of data and in writing the manuscript.

Availability of data and materials Not applicable.

\section{Ethics approval and consent to participate}

We will provide written information material to study participants and SP, who both must provide informed consent before data collection. The study protocol, informed consent forms, questionnaires, participant education and other requested documents were reviewed and approved by the medical ethics committee of the Medical Chamber of Hamburg (date: 19 November 2018, number: PV5910).

Consent for publication

Not applicable.

\section{Competing interests}

The authors declare that they have no competing interests.

\section{Author details}

'Department of Oncology, Hematology and BMT, Palliative Care Unit, University Medical Center Hamburg-Eppendorf, Martinistraße 52, 20246 Hamburg, Germany. ${ }^{2}$ Department of Medical Psychology, University Medical Center Hamburg-Eppendorf, Hamburg, Germany. ${ }^{3}$ Department of Palliative Medicine, University Medical Center Goettingen, Goettingen, Germany. ${ }^{4}$ Department of Hematology, Oncology and Tumor Immunology, Campus Kiel, University Medical Center Schleswig-Holstein, Kiel, Germany. ${ }^{5}$ Medical Department, Division of Hematology, Oncology and Tumor Immunology, Campus Virchow Clinic, Charite University Medicine Berlin, Berlin, Germany.

Received: 27 February 2020 Accepted: 22 April 2020

Published online: 12 May 2020

\section{References}

1. Harrison JD, Young JM, Price MA, Butow PN, Solomon MJ. What are the unmet supportive care needs of people with cancer? A systematic review. Support Care Cancer. 2009;17(8):1117-28.

2. WHO. Cancer Control: Knowledge into Action: WHO Guide for Effective Programmes: Module 5: Palliative Care. Geneva: WHO Press; 2007.

3. Ambroggi M, Biasini C, Toscani I, Orlandi E, Berte R, Mazzari M, et al. Can early palliative care with anticancer treatment improve overall survival and patient-related outcomes in advanced lung cancer patients? A review of the literature. Support Care Cancer. 2018;26(9):2945-53.

4. Bakitas MA, Tosteson TD, Li Z, Lyons KD, Hull JG, Li Z, et al. Early versus delayed initiation of concurrent palliative oncology care: patient outcomes in the ENABLE III randomized controlled trial. J Clin Oncol. 2015;33(13):1438.

5. Zimmermann C, Swami N, Krzyzanowska M, Hannon B, Leighl N, Oza A, et al. Early palliative care for patients with advanced cancer: a clusterrandomised controlled trial. Lancet. 2014;383(9930):1721-30.

6. Kavalieratos D, Corbelli J, Zhang D, Dionne-Odom JN, Ernecoff NC, Hanmer J, et al. Association between palliative care and patient and caregiver outcomes: a systematic review and meta-analysis. JAMA. 2016;316(20):210414.

7. Rugno FC, Paiva BS, Paiva CE. Early integration of palliative care facilitates the discontinuation of anticancer treatment in women with advanced breast or gynecologic cancers. Gynecol Oncol. 2014;135(2):249-54.

8. Vanbutsele G, Pardon K, Van Belle S, Surmont V, De Laat M, Colman R, et al. Effect of early and systematic integration of palliative care in patients with advanced cancer: a randomised controlled trial. Lancet Oncol. 2018;19(3): 394-404.

9. Temel JS, Greer JA, El-Jawahri A, Pirl WF, Park ER, Jackson VA, et al. Effects of early integrated palliative Care in Patients with Lung and GI Cancer: a randomized clinical trial. J Clin Oncol. 2017;35(8):834-41.

10. Greer JA, Pirl WF, Jackson VA, Muzikansky A, Lennes IT, Heist RS, et al. Effect of early palliative care on chemotherapy use and end-of-life care in patients with metastatic non-small-cell lung cancer. J Clin Oncol. 2012;30(4):394-400.

11. Brighton $L$, Bristowe K. Communication in palliative care: talking about the end of life, before the end of life. Postgrad Med J. 2016;92(1090):466-70.

12. Hagerty RG, Butow PN, Ellis PA, Lobb EA, Pendlebury S, Leighl N, et al. Cancer patient preferences for communication of prognosis in the metastatic setting. J Clin Oncol. 2004;22(9):1721-30.

13. Collins A, McLachlan SA, Philip J. Communication about palliative care: a phenomenological study exploring patient views and responses to its discussion. Palliat Med. 2018;32(1):133-42.

14. LeBlanc TW, Bloom N, Wolf SP, Lowman SG, Pollak Kl, Steinhauser KE, et al. Triadic treatment decision-making in advanced cancer: a pilot study of the 
roles and perceptions of patients, caregivers, and oncologists. Support Care Cancer. 2018;26(4):1197-205.

15. Ferrell BR, Temel JS, Temin S, Alesi ER, Balboni TA, Basch EM, et al. Integration of palliative care into standard oncology care: American Society of Clinical Oncology clinical practice guideline update. J Clin Oncol. 2017; 35(1):96-112.

16. Buss MK, Rock LK, McCarthy EP. Understanding palliative care and hospice: a review for primary care providers. Mayo Clin Proc. 2017;92(2):280-6.

17. Goulart BH, Reyes CM, Fedorenko CR, Mummy DG, Satram-Hoang S, Koepl $L M$, et al. Referral and treatment patterns among patients with stages III and IV non-small-cell lung cancer. J Oncol Pract. 2013;9(1):42-50.

18. Remi C, Simon S, Voltz R, Pralong A, Follmann M, Bausewein C. S3 Guideline "palliative care for patients with incurable cancer". Krankenhauspharmazie. 2017;38:413-22.

19. Gilligan T, Coyle N, Frankel RM, Berry DL, Bohlke K, Epstein RM, et al. Patientclinician communication: American Society of Clinical Oncology consensus guideline. J Clin Oncol. 2017:35(31):3618-32.

20. Jacobsen J, Jackson V, Dahlin C, Greer J, Perez-Cruz P, Billings JA, et al. Components of early outpatient palliative care consultation in patients with metastatic nonsmall cell lung cancer. J Palliat Med. 2011;14(4):459-64.

21. Mack JW, Cronin A, Taback N, Huskamp HA, Keating NL, Malin JL, et al. Endof-life care discussions among patients with advanced cancer: a cohort study. Ann Intern Med. 2012;156(3):204-10.

22. Granek L, Nakash O, Cohen M, Ben-David M, Ariad S. Oncologists' communication about end of life: the relationship among secondary traumatic stress, compassion satisfaction, and approach and avoidance communication. JPsychooncology. 2017;26(11):1980-6.

23. Almack K, Cox K, Moghaddam N, Pollock K, Seymour J. After you: conversations between patients and healthcare professionals in planning for end of life care. BMC Palliat Care. 2012;11:15.

24. Zhi WI, Smith TJ. Early integration of palliative care into oncology: evidence, challenges and barriers. Ann Palliat Med. 2015;4(3):122-31.

25. Baile WF, Lenzi R, Parker PA, Buckman R, Cohen L. Oncologists' Attitudes Toward and Practices in Giving Bad News: An Exploratory Study. J Clin Oncol. 2002;20(8):2189-96.

26. Cripe L, Frankel RM. Understanding what influences oncology clinicians' communicating with dying patients: awareness of one's own mortality may be one key. J Patient Educ Couns. 2016;99(3):307-9.

27. Draper EJ, Hillen MA, Moors M, Ket JC, van Laarhoven HW, Henselmans I. Relationship between physicians' death anxiety and medical communication and decision-making: a systematic review. J Patient Educ Couns. 2018.

28. Daugherty CK, Hlubocky FJ. What are terminally ill cancer patients told about their expected deaths? A study of cancer physicians' self-reports of prognosis disclosure. J Clin Oncol. 2008;26(36):5988-93.

29. Epstein RM, Duberstein PR, Fenton JJ, Fiscella K, Hoerger M, Tancredi DJ, et al. Effect of a patient-centered communication intervention on oncologist-patient communication, quality of life, and health care utilization in advanced Cancer: the VOICE randomized clinical trial. JAMA Oncol. 2017; 3(1):92-100

30. Goelz T, Wuensch A, Stubenrauch S, Ihorst G, de Figueiredo M, Bertz H, et al. Specific training program improves oncologists' palliative care communication skills in a randomized controlled trial. J Clin Oncol. 2011; 29(25):3402-7

31. Fujimori M, Shirai Y, Asai M, Kubota K, Katsumata N, Uchitomi Y. Effect of communication skills training program for oncologists based on patient preferences for communication when receiving bad news: a randomized controlled trial. J Clin Oncol. 2014;32(20):2166-72.

32. Kissane DW, Bylund CL, Banerjee SC, Bialer PA, Levin TT, Maloney EK, et al. Communication skills training for oncology professionals. J Clin Oncol. 2012; 30(11):1242.

33. Back AL, Arnold RM, Baile WF, Fryer-Edwards KA, Alexander SC, Barley GE, et al. Efficacy of communication skills training for giving bad news and discussing transitions to palliative care. Arch Intern Med. 2007:167(5):453-60.

34. Bernacki R, Hutchings M, Vick J, Smith G, Paladino J, Lipsitz S, et al. Development of the serious illness care program: a randomised controlled trial of a palliative care communication intervention. BMJ Open. 2015;5(10) e009032.

35. Moore PM, Rivera S, Bravo-Soto GA, Olivares C, Lawrie TA. Communication skills training for healthcare professionals working with people who have cancer. Cochrane Database Syst Rev. 2018;7:CD003751.
36. Gamondi C, Larkin P, Payne S. Core competencies in palliative care: an EAPC white paper on palliative care education: part 1. Eur J Cancer. 2013.

37. Möhler R, Köpke S, Meyer G. Criteria for reporting the development and evaluation of complex interventions in healthcare: revised guideline (CReDECI 2). J Trials. 2015;16(1):204.

38. Stevens MJ, Campion M. The knowledge, skill, and ability requirements for teamwork: implications for human resource management. J Manag. 1994; 20(2):503-30,

39. Berkhof M, van Rijssen HJ, Schellart AJ, Anema JR, van der Beek A. Effective training strategies for teaching communication skills to physicians: an overview of systematic reviews. Patient Educ Couns. 2011;84(2):152-62.

40. Cohen J. Statistical power analysis for the behavioral sciences. Hillsdale: Lawrence Erlbaum Associates; 1988:2.

41. Stubenrauch S, Schneid EM, Wünsch A, Helmes A, Bertz H, Fritzsche K, et al. Development and evaluation of a checklist assessing communication skills of oncologists: the COM-ON-checklist. J Eval Clin Pract. 2012;18(2):225-30.

42. Bieber C, Muller KG, Nicolai J, Hartmann M, Eich W. How does your doctor talk with you? Preliminary validation of a brief patient self-report questionnaire on the quality of physician-patient interaction. J Clin Psychol Med Settings. 2010;17(2):125-36.

43. Mason S, Ellershaw J. Assessing undergraduate palliative care education: validity and reliability of two scales examining perceived efficacy and outcome expectancies in palliative care. J Med Educ. 2004;38(10):1103-10.

44. Merrill J, Lorimor R, Thornby J, Woods A. Caring for terminally ill persons: comparative analysis of attitudes (thanatophobia) of practicing physicians, student nurses, and medical students. Psychol Rep. 1998;83(1):123-8.

45. Logemann T. General Data Protection Regulation. 2018. https:/gdpr-info. eu/. Accessed 29 Nov 2019.

46. Temel JS, Greer JA, Muzikansky A, Gallagher ER, Admane S, Jackson VA, et al. Early palliative care for patients with metastatic non-small-cell lung cancer. N Engl J Med. 2010;363(8):733-42.

\section{Publisher's Note}

Springer Nature remains neutral with regard to jurisdictional claims in published maps and institutional affiliations.

Ready to submit your research? Choose BMC and benefit from:

- fast, convenient online submission

- thorough peer review by experienced researchers in your field

- rapid publication on acceptance

- support for research data, including large and complex data types

- gold Open Access which fosters wider collaboration and increased citations

- maximum visibility for your research: over $100 \mathrm{M}$ website views per year

At $\mathrm{BMC}$, research is always in progress.

Learn more biomedcentral.com/submission 